\title{
CONCEPTO Y REALIDAD DE LA LEY NATURAL
}

Francisco Interdonato S.J.

\section{INTRODUCCION}

Los lusnaturalistas no han inventado la ley ni el derecho, pero sí la gloria de la ley y el derecho, que son la Ley Natural y el Derecho Natural. Tal gloria últimamente procede de su transfondo que es una concepción del hombre, una antropología y un proyecto sobre el mismo hombre, que no se satisface con constatar los Códigos, sistematizarlos, añadir nuevas nociones fácticas y narrar su historia. Va más allá. Se pregunta sobre el ser del derecho, su esencia auténtica, sus nexos, sus valores fundamentales, y así tematiza su naturaleza y su historicidad para llegar a establecer normas absolutas del actuar humano y principios de validez universal.

Tarea doblemente difícil hoy porque al tradicional "Positivismo Juridico" se le suman modelos de convicción muy difundidos que giran sobre enunciados pragmáticos. El lusnaturalista no puede someterse a tales modelos, más bien debe ayudar al derecho positivo a caer en la cuenta que está situado en un todo de mayor alcance: El Derecho Natural. A esto debe configurarse el Derecho Positivo para preservar su propio ser, responder a las preguntas últimas que inexorablemente se le plantean, $y$ entenderse plenamente a si mismo.

Lo que esto último implica, se puede ilustrar leyendo el Art. $2^{\circ}, 20 . a$. de la Constitución Nacional: "Nadie está obligado a hacer lo que la ley no manda, ni impedido de hacer lo que ella no prohibe". Esto no es verdad porque identifica el ámbito de lo legal con lo moral. Y si bien es cierto que lo primero (lo legal) entra en lo segundo (en lo moral), no es así lo contrario. No todo lo moral es legislable, ni todo lo que es inmoral puede ser prohibido por ley positiva. Más aún, el legislador humano no puede prever ni siquiera lo que cae en el ámbito legal. No obstante el poco tiempo transcu- 
rrido, los Constituyentes no pudieron anticipar las implicaciones legales de la presente "ingeniería genética": por ejemplo, si una mujer puede alquilar su útero a otra, y caso de que lo haga, si está obligada a entregar el hijo así engendrado; si el esperma es asimilable a una propiedad separable de la persona, que puede depositarse en un Banco, legarla en herencia (aun a la propia esposa), etc. Incluso entre los delitos conocidos, nadie podia sospechar el desarrollo del narcotráfico, las caracteristicas del terrorismo; si la legitimidad de la huelga se extendía a la de los médicos, a la de hambre. Acontecimientos históricos de gran repercusión, como la constitución del Tribunal de Nüremberg, quedaria injustificado, en el puro positivismo jurídico. Las situaciones creadas por la "suspensión de las garantías constitucionales" se justifican no por esa ficción juridica, sino en virtud de un principio primario de la Ley Natural: "Salus populi, suprema lex est" (El bien común, es la suprema ley).

Por falta de claridad en el planteamiento, suele suceder que se niegue la existencia de la Ley Natural con argumentos de pura Ley Natural. Tal sucedería si, por ejemplo, un Constituyente positivista diera las razones por las cuales aprueba o no aprueba un determinado artículo; si a otro se le pregunta si un náufrago en una isla de pocos habitantes, tendría derechos y deberes, no obstante la falta de ordenamiento jurídico; si un Gobierno tiránico dejaría de ser responsable de sus atropellos porque los cometió con sus leyes en las manos; o, en términos más generales, si un Gobierno legal (constitucional) puede llegar a ser ilegitimo.

Es indudable que todos admiten que la Ley o la Constitución, de por sí, no puede hacer justa cualquier acción; y que pertenece a la esencia del Estado humanista la existencia de un Poder Judicial independiente que medie entre el pueblo y su Gobierno, y que puede sentar en el banquillo al Poder Ejecutivo y aun al Legislativo. ¿Por qué es cierto todo esto? ¿Por qué son válidos principios como: "Debes, luego puedes"; o: "La necesidad no tiene leyes" y otros universalmente admitidos?

El breve escrito que sigue sobre "El concepto y la realidad de la Ley Natural", por estar injertado en el tronco de una secular reflexión, aspira a aportar una respuesta a esas preguntas. 
Se llama Ley natural, pero en un sentido completamente distinto que en las ciencias naturales. Su sujeto y destinatario es sólo el hombre, el único capaz de cumplirla libremente. A diferencia de los animales, que son de golpe lo que son, el hombre debe hacerse lo que es. Su ser de persona le es dado como "ya realizado" y como "misión" o tarea. Este enigma es su gloria, con tal que armonize en una síntesis superior estos dos existenciales opuestos: la inclinación permanente y profunda de su naturaleza al Bien; con la inclinación del momento, aquí y ahora, en contra de su bien. Esta paradoja la descubrió en sí Ovidio: "Veo lo mejor, lo apruebo; pero sigo lo peor" (1); pero pertenece a la historia de todo individuo, como lo atestigua San Pablo (Rom. 7, 15-17).

Justamente para que el hombre pueda dirigirse a ese fin con actos personales libres, necesita leyes. En efecto la Ley, como la definió esencialmente Santo Tomás, es: "Una ordenación racional, para el bien común, promulgada por el legítimo gobernante" (2). Esta definición, con tal de entenderse bien el tercer componente "promulgada por el legítimo gobernante", se puede aplicar tanto a la ley positiva como a la natural. Aquí nos ocuparemos primariamente de la ley natural. Esta, por su indole, no cabe estudiarla ya elaborada en los códigos (como la ley positiva); hay que descubrirla, reconocerla, en el corazón y en la conducta originaria de los hombres y las sociedades, previamente a su conceptualización y reflexión. Por supuesto que para reconocerla es necesario describirla; y para describirla tenemos que referirnos a los principales tratadistas (3). Pero esta descripción no es la meta ni vive de por sí; sólo tiene la función de conducirnos a su experiencia. No nos da el conocimiento de algo simplemente ignorado sino el reconocimiento de algo que ya sabíamos de modo implícito y vivido, de manera

(1) OVIDIO: "Metamorfosis" VII, 21: "Video meliora, proboque; deteriora sequor".

(2) S. Th. 1.2 q. 90 a. 4c. Para una visión más completa, leer las qq. 90; 91 y 93 .

(3) Arrancan desde Aristóteles; pero aquí nos remitimos sobre todo a Santo Tomás y los grandes iusnaturalistas y filósofos escolásticos de los siglos XVI y XVII, como Cayetano, Vitoria, Soto, Vásquez, Suárez, Lugo; y de los modernos, principalmente Maritain. 
natural, que es lo que precisamente dice la definición de Ley Natural: "Conjunto de juicios PRACTICOS por los cuales el hombre conoce NATURALMENTE el bien que NECESARIAMENTE debe hacer y el mal que debe evitar". Los tres elementos principales de la definición, resaltados con mayúsculas, constituirán otros tantos capítulos explicativos.

1. Juicios PRACTICOS, son los no teóricos o expresados. Uno los posee, quizá sin siquiera saber formularlos, pero que guían perfectamente su acción. No son normas para pensar, sino para actuar. Los tienen todos. aun los analfabetos, con tal de no haber sido sometidos a un proceso educacional positivamente perverso.

Por lo mismo que no son originariamente conceptos, es difícil explicar en qué consisten. Para aproximarnos, podemos decir que son juicios de la "razón práctica", en contraposición a la "razón especulativa". Esta construye juicios estrictamente universales y tiene por objeto esas verdades o "esencias universales" de las que tan bellamente habló Platón; y que en la historia de la filosofía, a partir del Nominalismo (fines de la Edad Media) constituyó un tema muy agitado bajo el nombre de "cuestión de los universales". El juicio de la "razón práctica", en cambio, versa sobre lo singular, lo individual, que si bien participa de la "esencia universal", está concretizado aquí y ahora; y su bondad o maldad moral se percibe de manera inmediata y no formulada.

2. Por los cuales conoce NATURALMENTE: Con esta expresión se significa que la Ley Natural es promulgada por la misma naturaleza del hombre. Esta notifica los preceptos primarios de dicha Ley, de manera espontánea, parecido a como se da cuenta, por ejemplo, que "el todo es mayor que la parte". Conocimiento que adquiere con tanta facilidad, que se diría innato, si por otras razones (no porque iría contra el conocimiento natural, ¡al contrario!) no constara que no existe conocimiento alguno innato. Lo que sí se puede decir innata es la inclinación a admitir la Ley Natural.

Tampoco cabría afirmar, en rigor, que se la conoce "por instinto". Eso sucede con los animales, en la medida en que de éllos se puede decir que tienen ley natural; y aun de los objetos inanimados, que por su esencia tienden necesariamente al fin que se le ha asignado. Pero éstas son leyes meramente ontológicas. La Ley 
Natural es ontológica y ética. Por eso Santo Tomás dice de ella que es: "La participación de la Ley Eterna en la criatura racional" (4). que por tanto requiere ser conocida y querida (cumplida) libremente y con lo cual el hombre llega a ser aquél que debe ser (aquél a que lo destina el Creador, añade el creyente).

Pero sea creyente o no, la conciencia moral natural se da en todos, y les dice lo que en cada situación debe hacer, no con conceptos articulados mediante un discurso racional, sino (de acuerdo con los términos usados por Maritain) "por inclinación", "por modo de instinto", o sea, por connaturalidad afectiva o tendencial hacia los fines del actuar humano. $Y$ añade ese gran tratadista del derecho natural en los tiempos modernos: "En realidad nos hallamos en presencia de juicios determinados por inclinaciones que están enraizados en la razón que opera de manera pre-consciente" (5); o, como prefiere decir otro Autor actual: "A mi parecer se trata del intelectus en contraposición con la razón discursiva" (6).

La operación del Intelectus ("Intus-Legere": Leer lo interno) es la intuición intelectual. Con esta intuición se legitiman, por ejemplo, los primeros principios de la razón (de contradicción, etc.). También Santo Tomás estableció este paralelismo: “. . . todo razonamiento se deriva de principios que nos son conocidos naturalmente, y toda apetición de las cosas que conducen al fin se deriva del apetito natural del fin último, y así también la primera orientación de nuestros actos al fin debe efectuarse mediante la Ley Natural" (7).

Hemos multiplicado expresiones y citas; pero todo puede reducirse a esto: Conocer NATURALMENTE significa que sin gran deliberación, o sin deliberación alguna, el hombre normal

(4) S. Th. 1-2 q. 91 a. 2 .

(5) MARITAIN, J.: "Neuf lezons sur la Philosophie morales" en "Oeuvres" T. II, p. 53.

(6) Franz Bockle; J. Th. C. Arntz y Oteos: "El Derecho Natural", Herder" 1971 , p. 88 .

S. Th. 1-2 q. 91 a. 2 ad 2. 
-no positivamente pervertido- conoce el bien y el mal . . ¿ Cuál bien y mal?

3. "El bien que NECESARIAMENTE debe Hacer y el Mal que debe Evitar": El Bien que Necesariamente debe hacer es aquél que, si lo omite, comete una culpa humana (ética) y moral (religiosa). Humana, porque va contra la autoperfección o desarrollo de su persona entendida integramente es decir, con todas sus relaciones: Consigo misma, con los demás y con Dios. Sería también culpa moral, religiosa (pecado) que impide alcanzar su último fin sobrenatural. Lo básico es lo primero, lo humano: La Ley Natural es ley del hombre; es la traducción en normas de la esencia permanente del hombre.

Que el hombre tenga una ESENCIA PERMANENTE, conforme a la cual se dan objetos y actos que son para todos y en todo tiempo y lugar buenas o malas, es el presupuesto de la Ley Natural. Porque esto es cierto, no es una ley en el sentido extrinsecista de la palabra. No es ley porque esté en un Código elaborado, o porque la haya impuesto la autoridad.

Es más bien una ordenación interior, realidad viviente; impresa (por Dios) en la criatura racional para guiarlo a la libertad y crecimiento total y en conexión con su fin penúltimo (en el tiempo) y último (en la eternidad). Por ello lo que prohibe no es malo "porque está prohibido", sino que "está prohibido porque es malo". No debe concebirse como una especie de gendarme que cohibe, sino como un pedagogo que conduce a la fuente del amor y el gozo.

Por cierto que la Ley Natural puede estar enunciada en forma de imperativos y preceptos prohibitivos: "No mates", "no robes", "no adulteres", y otras imposiciones negativas; pero su sentido último es siempre positivo: Esos deberes son una exigencia que emana del ser personal. Expresan lo que uno debe a los otros; y lo que los otros agentes racionales están obligados en consciencia a reconocerle a él.

Ahora bien, afirmar que la persona humana por su esencia, previamente a toda ley positiva, goza de derechos imprescriptibles. que reclaman ante sí y ante otros estima, custodia y realización, no es otra cosa que afirmar la existencia de la Ley Natural. Es esta 272 
Ley la que traduce esos derechos y prescribe esos deberes fundamentales, incluido el deber de respetar las leyes positivas. Estas. en efecto, obligan en consciencia en virtud de esa Ley Natural. Por cierto que las leyes positivas deben reconocer y tutelar los derechos fundamentales de. la persona, pero esos se dan porque le son inherentes y el hombre los tendrá aunque no hubiera ninguna ley positiva (humana o divina) que los explicite y mande. Anteriormente a toda codificación, el hombre en su saber acerca de su autointelección y autointerpretación, siempre ha sabido lo que es la libertad, la responsabilidad y lo que esto inmediatamente conlleva. Lo ha sabido con un conocimiento implícito en la autoconsciencia de su esencia permanente, aunque su conocimiento explícito, teórico, actual (en cada caso) y su autointerpretación, sea histórico.

Entendida así la esencia permanente no excluye sino incluye el que tenga aspectos cambiantes. Es claro que la autointerpretación, refleja, del hombre, tiene una historia larga y cambiante, a la que pertenece -según Rahver - también la historia de la revelación y de la teología cristiana ... pero esto mismo presupone una esencia permanente del hombre, que se mantiene a través de toda la historia. El cristiano, lejos de dudarlo, tiene una razón adicional perentoria para admitirlo: "Sin esa esencia universal y permanente no podrían todos los hombres ser realmente sujeto y objeto de la salvación una, por parte de uno y el mismo Dios en Jesucristo, a través de la misma historia salvifica" (8). Pero de suyo basta la literatura universal para probarlo: Si la naturaleza humana cambiara fundamentalmente, ahora no entenderíamos ni nos sentiríamos reflejados en la literatura del pasado (estos dos puntos últimos se ampliarán más adelante).

Una esencia igualmente permanente posee el Bien. Este no se identifica con "el amor a otra persona", "la fidelidad a sí mismo", u otros aspectos que están incluidos en el Bien, pero no son $\mathrm{el} \mathrm{Bien.}$ Este tiene una esencia permanente, eterna, infinita, que se realiza con matices en cada época y se explicita más o menos. Precisamente la consciencia es el lugar en que eso eterno irrumpe en el tiempo. Esta irrupción es la que tiene historia porque es objeto de la libre

(8) RAHNER, K.: “Escritos de Teologia" "Taurus" 1969, Vol. VI, p. 235. 
elección humana. Con la consciencia en hombre está abierto a la eternidad y, a la vez, está orientado al tiempo, al acontecer diario.

En su consciencia lleva una ley superior, no escrita c inmutable; una auténtica "invariante" del ser humano, como lo confirma la conclusión del psicólogo evolutivo de Harvard, Jerónimo Kagan, que acaso ni pensó en la ley natural, pero (como suele suceder) la afirma implícitamente: "No creo que la consciencia es aprendida o inculcada en el niño por los padres. Nuestra cultura hace algo muy dañino diciendo que la moralidad es aprendida. . Creo que todos los niños, con tal que tengan un sistema nervioso intacto, conocen antes de los tres años, que dañar, lesionar (hurting) a otro, es malo. Podemos esperar una consciencia en todo niño: No tenemos que edificarla o inculcarla. Lo único que debemos hacer es procurar un medio ambiente tal que no se la hagan perder' (9).

\section{DIFERENTES CLASES DE PRECEPTOS DE LA LEY NATURAL}

Que la Ley Natural sea invariante, no significa ni puede significar que todos sus preceptos tengan igual evidencia. En ningún Código sucede tal cosa; menos en éste que es conocido naturalmente. Su ser plural no se percibe de manera igualmente obvia y espontánea en todas sus partes o preceptos. Antes bien suelen distinguirse estas cuatro clases:

1. Preceptos Generalísimos o Principios Absolutos;

2. Preceptos Generales;

3. Aplicaciones a Acciones Genéricas;

4. Aplicaciones a Acciones Particulares.

1. LOS PRECEPTOS GENERALISIMOS: Son Principios Primarios de la razón práctica, evidentes por sí mismos, como por ejemplo: "Hay que hacer el bien y evitar el mal": "Hay que obrar según la razón", que inmediata y connaturalmente sabe cualquier ser humano.

(9) "TIME", Octubre 22, 1984, p. 46 (la versión inglesa puede verse allí mismo). 
2. PRECEPTOS GENERALES: Aplicando esos principios primarios a las relaciones con Dios, con los demás y consigo, toda persona, de manera fácil, inmediata, natural, puede deducir (no necesariamente conceptualizar con la razón teórica) que "Dios debe ser respetado"; "No hay que hacer mal a su prójimo"; "no dañarse a sí mismo".

3. APLICACIONES A ACCIONES GENERICAS: Son conclusiones de los preceptos anteriores que fluyen con rigor lógico; sin embargo, por el mismo proceso del raciocinio, aunque sea obvio y práctico, son, por su naturaleza, conclusiones y por tanto no pueden gozar de la evidencia natural de los principios de los cuales se derivan. Así del principio: "Dios, el hombre, deben, ser respetados" se deduce necesariamente: "No blasfemar"; "no matar", "no robar", y, general, los Diez Mandamientos (menos el $1^{\circ}$ ). Estas deducciones no están dotadas de la claridad evidente de los preceptos de $1^{\mathrm{a}}$ y $2^{\mathrm{a}}$ clase; pero participan de ellos en cuanto no necesitan de una elaboración propiamente científica y técnica. Cualquier mentalidad, aún primitiva, si está libre de prejuicios y vicios demasiado acusados, puede llegar a esas conclusiones mediante un discurso que por ser asistemático, natural, está al alcance de todos.

4. APLICACIONES A ACCIONES PARTICULARES: La piedra de tropiezo para entender y aceptar la Ley Natural la constituye esta $4^{\mathrm{a}}$ clase que, si bien son deducciones de los preceptos anteriores, requieren un raciocinio refinado, con aspectos obscuros, que sólo pueden descifrar mentes cultivadas, pues proceden no sólo de la razón práctica, sino también de la teorética, revestida de la ciencia moral y filosófico-jurídica. Su dificultad está en que no hay un descenso directo y univoco de los preceptos anteriores. Caben otras posibilidades. Un ejemplo que pone Santo Tomás, pero que resulta de actualidad, lo ilustra: "Nadie ignora que deben devolverse los bienes prestados: pero si devolverlos resultase perjudicial para la Patria... o si deben ser devueltos con determinada garantía o en determinada forma ... cuanto mayor número de condiciones se señala, mayor es el número de casos en que el principio puede fallar o no ser recto o verdadero" (10).

(10) S. Th. 1-2 q. 94 a. 4 c. 
De manera que en esa aplicación particular la conclusión puede ser, literalmente, contraria al principio general; y sin embargo, esencialmente, es conforme. No devolviendo lo prestado, cumple la Ley Natural plenamente entendida, es decir, en armonía con los otros principios y con el concepto mismo de Derecho que es "una facultad moral para algo". Pero queda claro que sólo hombres entendidos y humanamente maduros pueden instituir tal raciocinio $y$ sacar la consecuencia. Algo parecido sucede cuando del precepto de $3^{a}$ clase: "Honrar a los padres", se deduce la norma de $4^{a}$ clase de que hay que honrar también a los mayores de edad, a los de mayor dignidad, autoridad, etc. Las circunstancias de personas y otros adjuntos, pueden conducir a conductas opuestas y sin embargo legítimas según la Ley Natural.

La dificultad para reconocerlo es que actualmente, mucho más que antes, las circunstancias y adjuntos variables han crecido, y ha hecho el proceso deductivo más difícil y laborioso porque el descenso de los principios universales a los casos particulares, concretos, que en tiempo de Santo Tomás requería "una más sutil consideración racional por parte de los sabios" (11), se ha vuelto ahora mucho más complejo. En la misma medida en que el mundo ha crecido en posibilidades, ha crecido en el campo de lo elegible y con ello la cantidad de renuncias que supone cada elección. Han crecido, pues, las dificultades objetivas y subjetivas, como observa muy bien un Autor singularmente situado (hace poco fallecido): "Cuanto mayor es el ámbito de la libertad que el hombre crea para si activamente, más crece la opacidad de dicho ámbito, ya que en él se dan situaciones nuevas y que se encuentran en devenir, sobre las cuales sólo se habrá reflexionado plenamente cuando ya pertenezcan al pasado" (12).

En consecuencia, - diga lo que diga la ley civil-ahora es para todos más difícil alcanzar la "mayoría de edad". Si esta se define: "Lo que se exige de la expresa y libre responsabilidad de una persona en una determinada situación social o individual" (Rahner) se ve en seguida lo arduo que resulta abarcar la situación presente y decidir responsablemente. Por ejemplo: ¿Cómo discernir y padecer

(11) S. Th. 1-2 q. 1001.1 c.

(12) RAHNER, K.: “Escritos de Teología”, Taurus 1969, Tomo VI, p. 502. 
la inundación de estímulos?; ¿Cómo ganar e invertir el dinero?: ¿Qué oficio, profesión, Universidad, elegir? En la vida familiar, la elección del cónyuge, la planificación de la familia. En la vida nacional ¿por cuál partido o candidato votar? ¿cómo armonizar las libertades políticas con la paz social; el desarme con la seguridad? ¿Cómo hacer compatible el necesario progreso industrial con la protección del medio ambiente? ... ¿ No es claro que la complejidad y multiplicidad de todo nos hace incompetentes en muchas cosas?

En tal situación, además del valor moral y la determinación para cumplir la Ley Natural, se requiere esfuerzo decidido de informarse y sopesar las normas con postura crítica; saber defenderse contra la tiranía de la opinión pública; discernimiento y autodominio para no juzgar como moralmente legitimo todo lo útil o cómodo. Incluso para el creyente que atiende a las enseñanzas de la Iglesia, le resulta objetivamente más espinoso aceptarlas porque las encuentra debilitadas por el aumento impresionante del conocimiento profano; se da con una pluralidad de interpretaciones acerca de la inserción socio-política; la moral, etc.

A esas dificultades objetivas hay que añadir las subjetivas, inherentes a todo conocimiento orientado a la acción -como es la Ley Natural - que por tanto sufre el influjo de la voluntad, que a su vez es influida por la situación psicológica del individuo, esto es, por su vida afectiva, apetitos, instintos, pasiones, costumbres. La articulación armónica de tan diversos elementos e influjos, postulan un tratamiento teórico que a partir del conocimiento natural tiene que adentrarse cada vez más en el reino del conocimiento reflejo, hasta encontrar su asiento en la Ley Positiva. En cuyo caso Esta es, como debe ser, un desarrollo de las estructuras fundamentales de la Ley Natural, a la cual, de rechazo, contribuye a enriquecer.

Así entendido se da a través de la historia, un evidente desarrollo en el conocimiento de la Ley Natural; pero no de la misma índole que la información histórica que se adquiere acerca de las leyes establecidas por los legisladores humanos. La Ley Natural no es una ley escrita y no Comenzó cuando fué codificada. Lo que de Ella se ha escrito a lo largo de los siglos, es la reflexión categorial, explícita, de lo que siempre se había vivido y se había conocido 
con conocimiento transcendental o implicito. El iusnaturalista, el filósofo, el teólogo, se han esforzado en todo tiempo a dilucidar por qué tal juicio ético práctico se ha impuesto y se impone a la consciencia de los hombres. Su empeño se ha dirigido en justificar racionalmente las certezas existenciales poseídas en su comportamiento moral. Pero puesto que el conocimiento transcendental o implícito no contiene formalmente todo lo que con el tiempo se explicitará, se comprende que a medida que se ha ido enriqueciendo la experiencia moral de los hombres y de las sociedades, los preceptos fundamentales (como por ejemplo, "Hay que hacer el bien y evitar el mal") han encontrado campo de más amplias determinaciones, estimuladas tanto por las nuevas situaciones históricas como por el caudal de instrumentos conceptuales aportados por la misma reflexión, hasta llegar a determinaciones últimas que son ya de pura ley positiva. Estas en su particularidad no pertenecen a la Ley Natural porque no son proposiciones de contenido universal, ni son imperiosamente exigidas, con ligazón necesaria, por la naturaleza del hombre. Son individuaciones originadas por múltiples posibilidades particulares que reclaman otras tantas leyes positivas; por ejemplo, leyes comerciales, de tránsito, higiene, etc. Queda sin embargo entendido que toda ley positiva en su fundamento no es independiente de la Ley Natural. En efecto, si la ley positiva y el Derecho de Gentes (13) tienen real fuerza de ley, se imponen a la consciencia, es en virtud de la Ley Natural. Esta es la que manda que todo aquel ordenamiento jurídico que Ella (en cuanto Ley Natural) deja indeterminado, sea ulteriormente particularizado por la ley positiva.

Estas últimas determinaciones, claro está, no se captan por inclinación, sino por el camino del conocimiento conceptual, ya que abarcan y reglamentan la vida cotidiana de los ciudadanos cada vez más diversificada, que demanda la ley positiva a fin de proteger los derechos naturales del hombre: Su libertad en primer lugar, y luego la salud, esparcimiento, seguridad en el tránsito y tantas otras que dependen del crecimiento de la población y del consumo en todas sus formas. Este crecimiento y diversificación de la sociedad multiplica las leyes, Códigos y aun "Declaraciones de Derecho". La toma de consciencia progresiva permite descubrir no exactamen-

(13) "Ius Gentium", "Derecho de Gentes" llamó Ulpiano al derecho que regula la vida en sociedad. En este sentido lo usamos aquí, aunque no hay uniformidad en los Autores. 
te "nuevos derechos", sino explicitar aquellos que antes no se habian percibido reflejamente por no darse las condiciones. Representándolo con un ejemplo, tomemos las palabras de San Pablo: "En verdad, cuando los gentiles, guiados por la razón natural, sin ley (se entiende positiva) cumplen los preceptos de la ley . . . muestran que los preceptos de la ley están escritos en sus corazones" (Rom. 2: 14-15); pero él no enumera la variedad de esos preceptos escritos en su corazón, ni podría hacerlo, no porque aumenten ellos mismos, sino porque aumenta la toma de consciencia de ellos al contacto con sucesivas realidades que introducen nuevos factores o suprimen otros.

E1 "aumento de toma de consciencia" bien entendida no merma la propiedad fundamental que vamos a exponer a continuación:

\section{LA LEY NATURAL NO PUEDE SER IGNORADA NI LO $H A$ SIDO DE HECHO:}

Sólo si es, y ha sido, históricamente así, se puede concluir: "Luego se da" o "efectivamente está escrita en sus corazones". Más que algo ha sido ya dicho; con todo es necesario recapitularlo y mostrar ex-profeso que la Ley Natural por fundarse en la esencia permanente del hombre (14) tiene que ser universal en el espacio y en el tiempo. En otras palabras, que ningún hombre normalmente desarrollado, es decir, que no haya sido positivamente pervertido, pudo ignorar o ha ignorado las tres primeras clases de preceptos. Respecto de la cuarta hemos visto suficientemente por qué y cómo puede ser ignorada sin menoscabo de su plena vigencia.

Igualmente debe prenotarse que, al decir que no puede ser ignorada, se entiende con ciencia ejercida, práctica, no refleja y teórica. Con esta última -como en cualquier otra categorización de un conocimiento transcendental-, son posibles diversas y aun contrarias conceptualizaciones; pudiendo darse el caso de negar temáticamente (o categorialmente) lo que se admite atemáticamente (o transcendentalmente). $Y$ de hechos ¡cuántos han negado y niegan la Ley Natural con argumentos pertenecientes rigurosamente a la Ley Natural!

(14) Que el hombre tiene una "esencia permanente", es decir, que su naturaleza es inmutable, será tema del último capítulo de esta exposición. 
Otra advertencia básica es evitar el garlito de confundir la violación de la Ley Natural con el ignorarla. Se enfatizó arriba (15) que no basta conocer el bien para realizarlo. La Ley Natural ha sido y es violada ignomiosamente, pero (ejercitadamente) a sabiendas, como agudamente hace notar San Agust ín: "Ciertamente, Señor, que tu ley castiga el hurto, ley de tal modo escrita en el corazón de los hombres, que ni la misma iniquidad puede borrar. ¿Qué ladrón hay que sufra con paciencia a otro ladrón?" (16). De aquí que este Mandamiento ("No robar") - no menos que los otros- si bien por estar en las Sagradas Escrituras son imperativos de la ley positiva divina; por su naturaleza intrínseca, tales imperativos son objetivaciones de la propia esencia natural del hombre. Antes de ser verdades cristianas, son verdades humanas.

Lo cristiano no niega, sino supone lo humano. Tanto que Bernanos pudo decir que la dificultad de hacer del mundo moderno un mundo cristiano está en que el mundo moderno no es humano. Si no obstante Dios ha elevado esas objetivaciones naturales (los Mandamientos) a la dignidad de verdades reveladas, no ha sido porque de por sí sean inaccesibles a la razón natural, sino, como dice el Vaticano $1^{\circ}$ "Para que pueda ser conocido por todos aun en la condición presente del género humano, de modo fácil, con firme certeza y sin mezcla de error alguno" (17).

El ser accesible a la razón humana no significa, empero, que la Ley Natural haya sido traída al mundo por la mano desfalleciente del hombre. Su origen está en Dios y su observancia entra dentro del orden salvífico. De aquí se deriva una prueba apodíctica de que la Ley Natural no puede ser ignorada, y es que su ignorancia negaría la Providencia de Dios y vaciaría de sentido su Ley Eterna. Esta, por una parte, manda conservar y prohibe perturbar el Orden Moral Natural; y por otra, le ocultaría o dificultaría su conocimiento. O, como lo formula Rahner: "De lo contrario no podrían todos los hombres ser realmente sujeto y objeto de la salvación una

(15) Cfr. la Nota (1).

(16) SAN AGUSTIN: "Confesiones" II, 4, 9.

(17) DFNZINGER (Dz) “El Magisterio de la Iglesia” No. 1796. 
por parte de uno y el mismo Dios en Jesucristo, a través de la misma historia salvífica" (18).

En seguida se objetará que ese argumento es válido sólo para el creyente. No es poco. Pero de todas maneras no es válida la objeción. Según la consideración originaria, fenomenológica, -como se ha hecho arriba-quedó manifiesto que la Ley Natural no supone la existencia de Dios, sino, en todo caso, la prueba (19). Recuérdese lo dicho al exponer el segundo elemento de la definición, esto es, que el hombre la conoce naturalmente. Los lugares en que se ha hecho intervenir a Dios, aunque ontológicamente son de importancia suprema; lógicamente (en el orden del conocimiento) no son premisas; y podrían omitirse. Por ejemplo, cuando Santo Tomás dice: "La promulgación de la Ley Natural consiste en el hecho mismo que Dios imprimió en las mentes de los hombres el conocer naturalmente" (20), si se suprimera el inciso: "que Dios imprimió", la afirmación dè que el hombre la conoce naturalmente quedaria intacto de iure y de facto porque es un hecho que la humanidad nunca la ha ignorado. Lo primero se ha probado ampliamente. Contra lo segundo se yerguen dificultades históricas, siendo la más frecuente y la que realmente la estremece, la existencia legitimada de la esclavitud. Se impone tratarla con la amplitud necesaria.

\section{LA OBJECION DE LA ESCL.AVITUD}

Conforme a la doctrina expuesta de que los tres primeros preceptos de la Ley Natural no pueden ser ignorados a no ser por alguien sometido positivamente a una educación perversa y pervertidora (imposible de pensar en este caso tan generalizado) la objeción sólo tiene respuesta si la esclavitud, en la época en que se vivió, era de facto un precepto de cuarta clase, que por tanto pudo obscurecerse e ignorarse inculpablemente por diversas razones objetivas. Creemos que se puede mostrar suficientemente que es así. Las razones principales son las que vamos a exponer y deben tomarse en su conjunto.

(18) RAHNER, K.: "escritos de Teología” V1, pág. 235.

(19) No es este el lugar para exponer el "Argumento Etico" para probar la existencia de Dios.

(20) S. Th 1-2 q. 90 a. 4 ad. 1. 
En primer lugar el término esclavitud no era univoco y no permite identificarlo (como estamos inclinados a hacer ahora) con cl derecho de propiedad (21) sobre una persona en cuanto tal. Más aún, si el amo era un hombre recto, el esclavo no difería mucho del actual sirviente doméstico o trabajador permanente (22).

En segundo lugar la acepción generalizada de la esclavitud no era necesariamente por un acto positivo, sino una tolerancia sociológica de su existencia de facto, por el peso de la costumbre, el ejemplo de otros y las leyes de facto existentes con su inmenso valor pedagógico que inclinan a considerar legitimo lo que es legal (23).

Un caso aparte en el fenómeno de contemporizar con lo existente, es el de San Pablo, donde obran razones de muy distinta indole. El es el único Autor del Nuevo Testamento que toca el tema de los esclavos, sin pronunciarse acerca de la legitimidad o no legitimidad. El proclama el valor de la Fe y la perseverancia en Ella, para lo cual ningún estado de vida o institución debe ser ni condición ni estorbo. Tanto más cuanto San Pablo al escribir eso en la Primera Carta a los Corintios (7: 18-22), que data del año 57, parece que todavía contaba con que era inminente la Segunda Venida de Cristo que había afirmado cuatro años antes en su primer escrito (1 Tes. 4: 17).

Sea lo que sea, su doctrina directa era que en Cristo todos formamos "un cucrpo: Judios, griegos, esclavos y libres" ( 1 Cor. $12,13)$ que mantendrá constante: "Ya no hay judio ni griego; ni esclavo ni libre; ni hombre ni mujer, ya que todos vosotros sois uno en Cristo Jesús" (Gal. 3: 28). Más o menos iguales términos en Col. 3: 11 . Esto no implica una toma de posición explícita respec-

(21) El Derecho Romano definía lo propiedad: "Ius utendi et ABUTENDI" (derecho de usar y abusar de lo suyo). Lo segundo no se daba (legalmente) sobre el esclavo.

(22) Asley Wilkes al final de "Lo que el viento se llevó", nostálgico de que se llevara también la cultura sureña, responde a la objeción de la esclavitud: "Los tratábamos bien"; por lo menos en su caso debió ser cierto, pues luchaban a su lado.

(23) Actualmente sucede así en los Países que han legalizado el aborto, o tiende a serlo. 
to de la esclavitud. ¿Debía tomarla? No se sigue, pues ni aun en Col. 3: 11. Esto no implica una toma de posición explícita respecto de la esclavitud. ¿Debia tomarla? No se sigue, pues ni aun en ciertos estados existenciales (1 Tes. 4: 15) o prácticas ( $1 \mathrm{Cr} .15$ : 29) que caían en el ámbito religioso, lo hizo; cuanto más con la esclavitud que primariamente ca ía en el ámbito civil. Pablo no considera misión suya el condenarla, y menos el aprobarla; sino anunciar la Revelación sobrenatural de Cristo, dentro de la cual no caía lo que es de Ley Natural (Lc. 12: 14), no porque no deba imperarse o no sea salvífica, sino porque Cristo no se encarnó para enseñar lo a sequible a la razón humana (24) o substituirse El a lo confiado a los hombres (Gen. 1: 26-28).

Pero indirectamente la doctrina de San Pablo es incompatible con la esclavitud. Sólo que esta conclusión la tenía que sacar el hombre, entre otras cosas, para que sea meritoria. Esto es lo que propone a Filemón cuyo esclavo prófugo, Onésimo, se refugió cerca de él. No obstante que, tratándose de un amo cristiano Pablo sabe que puedo "mandarte lo que conviene, prefiero más bien rogarte en nombre de la caridad" (Fil. 8: 9). Se lo devuelve "no como esclavo, sino como un hermano querido ... en el Señor" (v. 16) (25).

(24) S. Th. 1-2 q. 2 a. 2 ad. 1 .

(25) La Iglesia posterior, una vez institucionalizada y por lo mismo inmersa en todas las dimensiones de la sociedad civil, tuvo que tomar más partido y lo hizo en todos sus niveles:

a) Nivel de la Jerarquía: Decenas de Concilios particulares impusieron penitencias y aun excomuniones (con lo que entonces esta pena implicaba) por rapar (práctica ignominiosa) a un esclavo; por golpearle causándole daño, y, peor aún, en caso de muerte. El Papa Adriano precisó que la indisolubilidad del matrimonio de los esclavos rige aun cuando se hayan casado contra la voluntad de sus amos.

b) Nivel de los Teólogos: Baste citar el núcleo teológico de las dos mayores cimas: San Agustín: "Esto es prescripción del orden natural. Así creó Dios al hombre. . . Y quiso que el hombre racional, hecho a su imagen, dominara únicamente a los irracionales, no el hombre al hombre, sino el hombre a la bestia" (Ciudad de Dios "Lib. XIX Cap. 15).

Santo Tomás: Desarrolla y precisa el pensamiento de San Agustín. Distingue el dominio de un hombre sobre otro en propio provecho; $y$ lo condena como fruto del pecado. En cambio el dominio de un hombre sobre otro para el bien del otro (por tanto sin reducirlo a 
Esta verdad revelada de que delante de Dios todos somos hermanos - no sólo iguales- eliminó de hecho (en el corazón y en el designio de conducta personal) la esclavitud. ¿Por qué tardó siglos en desaparecer de derecho? Porque hizo falta la mediación de progreso técnico y cosmovisional.

Por duro que resulte reconocerlo, antes de la máquina el trabajo de los esclavos fue la condición del progeso. Eran numerosisimos (algunos poseían hasta centenares) y, además de trabajar la tierra, ejecutaban todos los oficios mecánicos. Puede ayudar, para formarse una idea aproximada, lo que sucede ahora, por ejemplo, en el mismo Perú. Debido al escaso adelanto técnico aun familias modestas tienen sirvientes en casa. Y nadie lo considera de por sí (es decir, con tal que se los trate como personas y se respeten sus derechos humanos) inmoral o malo. Y sin embargo ¿cómo se mirará esta práctica dentro, pongamos, un siglo? De hecho un famoso iusnaturalista del siglo XVI Domingo de Soto, con estas razones ligaba a la economia y régimen de trabajo, justificaba la servidumbre o esclavitud (26). Además de condición del progreso material, lo fué también del arte típico de la antigüedad, la Arquitectura. Ahora admiramos la Acrópolis, las Pirámides, Macchu Picchù ... ¿Quién los hizo?: “ ¿Devuélveme el esclavo que enterraste!” (Neruda).

Si uno no quiere ser víctima del "provincialismo histórico", del no ver más allá de su horizonte inmediato, podrá lamentar que se hayan dado épocas tan duras, pero no las juzgará por las nuestras. Considérese sólo el cambio radical de nuestra cosmovisión so-

servidumbre) lo considera legítimo y dice que habría existido aun en el estado de justicia orignal (S. Th. 1 q. 96 a. 4).

c) Nivel de la Iglesia Toda: Baste recordar su tesón y gastos en manumitir esclavos y en redimir cautivos, hasta fundar Ordenes Religiosas con ese propósito específico. Naturalmente todo esto no es posible tratarlo aquí, ni necesario. Remitimos sin embargo a un libro claro, de fácil acceso: BALMES, Jaime: “El Protestantismo Comparado con el Catolicismo", B.A.C. No. 1949. Los Caps. XV-XIX. En apéndice, trae los cánones de los Concilios (pp. 181-202).

(26) No pudiendo extendernos demasiado, nos limitamos a remitir a la obra de DOMINGO DE SOTO: "De la Justicia y el Derecho", Libro IV cuestión 2da. art. 2 (Ed. B.A.C. Vol. 472 ; No. $570 ; 578$. 
bre la esclavitud obrado por la perspectiva evolucionista. La metafísica no depende de las ciencias; por eso la caida de la "Física" de Aristóteles no arrastró ninguna de sus grandes tesis filosóficas. En cambio sí depende la metafísica aplicada, como es la filosofía socio-política.

Para Aristóteles, como para todo el pensamiento griego, la historia era cíclica y retornaba. Por consiguiente no se proponian cambiar el mundo. De lo cual se siguió la desvalorización del trabajo, el relegarlo a los esclavos. Coincidían asi el concepto de trabajador y esclavo y se condicionaban mutuamente, de manera que la institución de la esclavitud aparecía tan necesaria como la del trabajo, y era coextensivo con él en todos los ámbitos de la producción y el servicio. No así el ciudadano. Este vivía de por sí en la ciudad (Polis) y se ocupaba de la politica (vida ciudadana en su amplio sentido). En efecto la ciudad y la política eran el medio humano de la vida y expansión del cindadano. Las grandes monarquías e imperios fueron cosmopolis (ciudades grandes) (27).

Los pensadores cristianos medievales, no obstante haber aprovechado el derecho natural estóico, que habia añadido al de Aristóteles esa especie de universalismo alcanzado por los Sofistas, que tuvo su cima en la "Nova Stoa" (romana) con Marco Aurelio y Séneca, en el aspecto de que tratamos no sobrepasaron su época. Produjeron la llamada "theopolítica" que consideraba el orden sociopolítico como estático y fijo. Si fallaba, el remedio no se buscaba en el progreso, en la transformación revolucionaria, sino en la reforma o sea, exactamente, en la vuelta al pasado, "al principio", donde situaban el modelo perfecto. Las polémicas socio-políticas versaban sobre el tiranicidio o la resistencia al tirano; pero, observa Congar; "Esta resistencia iba contra personas que faltaban a la justicia objetiva, pero no era aún la idea moderna de Revolución. . . previeron una legitimidad de la insurrección, pero pensando en la rebelión contra un jefe" (28).

(27) Un estudio histórico más completo se puede ver en AUBERT, Jean-Marie: "Le Droit Naturel, Ses Avatars Historiques et Son Avenir", "Supplement de la Vie Spirituelle", 1967 (81) págs, 282-323.

(28) CONGAR, I.: "Dos factores de sacralización en la vida social de la Edad Media". "Concilium" 1969 (47) p. 66. 
La idea del cambio radical, de la revolución. vino con la mentalidad evolucionista que proyectó la "edad de oro" al futuro. La "sociedad perfecta". No había que restaurarla, sino crearla.

A este orden de pensamientos y a esta situación objetiva hay que referir toda consideración acerca de la esclavitud. Se esforzaron en corregirla, en mejorarla, no simple y llanamente en abolirla, cómo se pensó al cambiar la perspectiva histórica y la realidad objetiva, a causa del desarrollo técnico y la nueva cosmovisión que produjo.

Con esta larga digresión creemos que se ha mostrado suficientemente -si se toma en su conjunto- que la existencia de la esclavitud no constituye una negación de alguna de las propiedades fundamentales de la Ley Natural en sí, que hemos visto. Nos falta ver ahora, para concluir, la propiedad correlativa del sujeto de la Ley Natural del hombre.

\section{LA IVMUTABILIDAD DE LA NATURALEZA HUMANA COMO FUNDAMENTO DE LA INMUTABILIDAD DE LA LEY NATURAL}

Más de una vez a lo largo de este estudio hemos afirmado que el hombre tiene una "esencia permanente". Lo que se ha dicilo de paso, debe ahora fundamentarse: La Naturaleza humana es inmutable en su ser fundamental, es substancialmente la misma antes como ahora, allí como aquí.

Como punto de partida, recordemos que la Naturaleza Humana completamente considerada (es decir en sus relaciones consigo, con los demás y con Dios o cualquier instancia transcendente) es la Norma de Moralidad, es decir, aquello a que los actos humanos deben conformarse para que sean rectos. Ahora bien, si, como se ha mostrado, la Ley Natural (en sus tres primeras clases de preceptos) es inmutable porque versa sobre actos que por naturaleza (no por las circunstuncias de tiempo y lugar) son buenos o malos, se sigue que debe darse una naturaleza liumana, asimismo inmutable.

Como primera prueba, sirva este texto de Canus que va más allá de su sobrio enunciado: "El análisis de la rebelión lleva por lo menos a la sospecha de que hay una naturaleza humana como lo 
pensaban los griegos, y contrariamente a los postulados del pensamiento contemporáneo. ¿Por qué rebelarse si no hay, en sí, nada permanente que preservar?" (29); y, se puede añadir, "nada permanente que violar". En efecto, si no se dieran" derechos de validez universal, anteriores y superiores al Estado" (30), por tanto inherentes a la naturaleza humana por ser tal, ¿cómo saber que un gobierno tiránico los viola?

Esa naturaleza humana constante no sólo la pensaron los griegos. También Santo Tomás: "El comprender los primeros principios es inherente a la naturaleza humana que es la misma en todos" (31). Y todos los iusnaturalistas. Pero no sólo. Ellos la han pensado. o sea, llevado al pensamiento reflejo; el resto de la humanidad la ha admitido implicitamente, ejercitadamente, por ejemplo, siempre que han reclamado su propiedad legítima, defendido su libertad de consciencia y de pensamiento, reivindicado su participación directa o indirecta en el Gobierno, etc. Acerca de todo esto ha habido y habrá variaciones en el cómo y el cuánto: pero su contenido fundamental ha sido y será consubstancial a la naturaleza del hombre. Tanto que Santo Tomás en esa parte de la Suma que trata de la Ley Natural, a la que pertenecen los Preceptos del Decálogo, afirma que éstos no pueden ser dispensados ni por Dios (32); y en ese sentido resuelve las dificultades suscitadas por la narración bíblica del sacrificio de Isaac (Gen. 22), el despojo de los egipcios (Ex. 12: 35-36), y el matrimonio de Oseas (Os. 1: 2). Dios -interpreta Tomás- en esos casos determinados cambió la materia moral y por eso deja de obligar. No porque haya mudado la Ley Natural o porque la haya dispensado. Sin duda la explicación exegética que da (33) puede progresar o cambiar; pero lo decisivo queda: Entonces, como antes y como ahora, la violación de los preceptos de $3 \mathrm{ra}$. clase de la Ley Natural -como el homicidio, el robo, el adulterio-, si son realmente tales, son siempre moral-

(29) CAMUS, A :: "L'Homme Revolté", "(iallimard", 1951, p. 28.

(30) Preámbulo de la Actual Constitución Peruana.

(31) S. Th. 2-2 q. 5 a. 4 ad 3: "aequaliter in omnibus invenitur'.

(32) S. Th. 1-2 q. 100 a. 8 ad 3.

(33) S. Th. 1-2 q. 94 a. 5 ad. 2. 
mente malos porque contrarios a la perfección de la naturaleza del hombre completamente considerada.

Y esta conclusión no está vinculada ni al mundo bíblico ni a la Revelación Religiosa. El Decálogo no es conforme a la naturaleza humana porque está revelado por Dios; sino que está revelado por Dios porque es conforme a la naturaleza humana. Lo propio ha de decirse de tantas disposiciones de otros antiquísimos Códigos religiosos o profanos, del Juramento de Hipócrates, el Derecho Romano, etc.: Su vigencia prueba la persistencia de la naturaleza humana. Si ésta cambiara, ahora nos servirian para contemplarlos en los museos como los coches de esa época.

Más clara prueba ofrece la Literatura, que Solzhenitzin definía como "historia del alma popular". Es un hecho que nosotros ahora entendemos y vibramos con los mismos sentimientos, pasiones, amores (y odios) que viven en los personajes de los Autores del pasado, aun los más antiguos que se conservan: Homero, Hesíodo, Virgilio. Con más impacto, los caracteres creados por los dramaturgos desde la más remota antigüedad griega: Esquilo, Sófocles, Eurípides, tan vivos como los del siglo XVI - Shakespeareo del siglo XX. La conclusión es la misma: Si la naturaleza cambiara, toda esa herencia cultural se habría detenido a las puertas de nuestro mundo cerrado. Nosotros no estaríamos situados ante el todo de la realidad humana. No entenderiamos el mensaje de ninguno de esos héroes prototípicos; y nos habríamos olvidado de nosotros mismos. El pasado sería una señal y una voz no oída ya por nadic. Lo habríamos olvidado, y habriamos olvidado incluso que hemos olvidado.

Reduciendo todavia más la perspectiva del tiempo, en un ámbito más gráficamente verificable, el de la más reciente de las artes, el Cine, nos hallamos con idéntica experiencia. Las películas del cine mudo nos parecen antidiluvianas por su técnica (porque la técnica sí cambia); pero el ser huma no no actúa en "Juana de Arco", "Ordet", "Fausto", "Nosferatu", "Napoleón", y tantas otras obras maestras de ese cine auroral, prueban que el hombre es eterno; y la Ley Natural, también. (34).

(34) Por tanto, sin necesidad de abrir capítulo aparte, queda excluido el lla- 
Las inmortales palabras de la Antigona de Sófocles son un permanente monumento y resumen que ilustrará lo dicho. Responde a Creonte que la increpa: "Sabías que estaba prohibido (enterrar a Polinice, hermano de Antígona) \&Y te atreviste a violar tales leyes?: ". . no creí que tus bandos habian de tener tanta fuerza que habías tú, mortal, de prevalecer por encima de las leyes no escritas e inquebrantables de los dioses. Que no son de hoy ni son de ayer, sino que viven en todos los tiempos y nadie sabecuándo aparecieron. No iba yo a incurrir en la ira de los dioses violando esas leyes por temor a los caprichos de hombre alguno".

$\mathrm{Si}$ al conjuro de esas palabras nos sentimos atravesados por la misma emoción que las inspiraron y no vacilamos en asentir, significa que son metatemporales y metaespaciales, y que Antígona no es sólo la heroína de la Ley Natural, sino la naturaleza humana eterna que reverdece y se agita incesantemente en cada uno de nosotros.

mado "POSITIVISMO JURIDICO" o doctrina que no admite más que el Derecho o ley positiva. Esta ni siquiera podría existir sin Ley Natural. La facultad o poder de crear leyes positivas, procede de un derecho o ley previa, no escrita, pero que todos admiten. Sólo a su luz cabe considerar injusta una ley positiva. Si ésta fuera la única fuente de lo justo, cualquier cosa que permitiera, ¡sería buena! El estado nunca sería responsable, ¡bastará con dar una ley para legitimar cualquier atropello o entreguismo! 